\title{
Physico-chemical studies of sorption materials based on biomass waste
}

\author{
Yulia Smyatskaya ${ }^{1, *}$, Natalia Politaeva ${ }^{1}$, and Liliya Mukhametova ${ }^{2}$ \\ ${ }^{1}$ Peter the Great Saint-Petersburg Polytechnic university, Saint-Petersburg, Russian Federation \\ ${ }^{2}$ Kazan State Power Engineering University, Kazan, Russian Federation
}

\begin{abstract}
This article discusses the possibility of using cheap raw materials for the treatment of wastewater from heavy metal ions using residual biomass and agricultural waste (sunflower husk, millet, buckwheat). Residual biomass is formed after the extraction of valuable components from microalgae and duckweed. The authors proposed to modify the sorption material using heat treatment and the introduction of additives, such as chitosan and thermally expanded graphite. Chitosan allows you to get sorption materials in the form of granules, which are convenient to use. The physicochemical properties of sorbents were studied. The sorption capacity for the obtained materials was from 5.0 to $32.0 \mathrm{mg} / \mathrm{g}$.
\end{abstract}

\section{Introduction}

The problem of wastewater treatment is relevant for the whole world. The greatest attention is paid to cheap water purification methods. The manufacture of sorption materials from waste allows us to solve two problems at once: water purification and waste disposal. Many research papers have been published in which it is proposed to use waste from various industries as sorption materials $[1,2,3]$.

In the works of Finnish scientists studied the modification of peat and sawdust with hydrochloric and citric acid [4].

Turkish scientists have studied the use of tea waste as a biosorbent. The optimum $\mathrm{pH}$ and temperature were selected for the extraction of copper and nickel ions, which were 5 and $50{ }^{\circ} \mathrm{C}$, respectively. The samples used for treatment of wastewater to remove the heavy metal ions have been obtained by the following procedure: prewaste of tea was washed and dried in an oven at a temperature of $105^{\circ} \mathrm{C}$. The sorption capacity for nickel ions of $10.8 \mathrm{mg} / \mathrm{g}$ and for copper ions of $14.9 \mathrm{mg} \mathrm{g}-1$ was achieved [5-6].

Known work [7-8], in which it is proposed to use as a sorbent feathers of Dromaius novaehollandiae (DNF) were collected from poultry and chitosan. As a result of this technology, it is possible to obtain a biopolymer composite having a sorption capacity $70.42 \mathrm{mg} / \mathrm{g}$ ).

Coffee grounds are a cheap sorption material for the treatment of wastewater from lead and fluoride [9]. The exhausted coffee grounds gathered from industrial wastes have been acid-activated and examined for their adsorption capacity. The surface morphology and elemental characterization of pre-and-post adsorption operations by FESEM, EDX and FTIR spectral analysis confirmed the potential of the exhausted coffee ground as successful bio-sorbent. However, thermodynamic analysis confirmed the adsorption to be spontaneous physicosorption with Langmuir mode of homogenous monolayer deposition. The kinetics of adsorption is well defined by pseudo second order model for both lead and fluoride. A significant quantity of lead and fluoride is removed from the synthetic contaminated water by the proposed bio-sorbent with the respective sorption capabilities of $61.6 \mathrm{mg} / \mathrm{g}$ and $9.05 \mathrm{mg} / \mathrm{g}$.

For the extraction of nickel (II) ions from aqueous media, a chitosan-based biopolymer coated with a layer of calcium and silicon alginate is effective. The adsorption of metal ions depends on the amount of adsorbent, the concentration of metal ions, the time of mixing and the $\mathrm{pH}$ of the solution. The maximum cure efficiency of nickel (II) ions was found at $\mathrm{pH}$ 5.0. The adsorption equations were well correlated by the Langmuir equations and the Freundlich isotherm. The maximum sorption capacity was $254.3 \mathrm{mg} / \mathrm{g}$ for a chitosan-based biosorbent coated with a silicon layer [10].

Marine plants are also widely used to extract heavy metal ions of zinc and copper [11,12]. The use of living algae is not advisable, therefore it is proposed to use dry algae as a sorbent. The walls of algae cells contain mainly cellulose and proteins associated with polysaccharides. Cell walls play a key role in the removal of heavy metals from water. In different types of algae, the composition of the cell wall is different, hence the ability to bind metal ions.

As a rule, cell walls are rich in functional groups such as carboxyl, amines, hydroxyls, phosphates, imidazoles and sulfates. These groups are negatively charged and attract positively charged metal ions. However, at low $\mathrm{pH}$, they are partially protonated and lose some strength to absorb positive ions. In [13], the

\footnotetext{
* Corresponding author: Makarovayulia169@mail.ru
} 
microalga strain Chlorella Sorokinianian was used, biomass was grown in cultivators, then dried in a drying cabinet and used to extract gallium ions. The sorption capacity was $38.5 \mathrm{mg} / \mathrm{g}$.

The study [14] directed the study of the biosorption of lead, cadmium, copper and arsenic ions using natural algae. The biosorption of these metals is based on an ion exchange mechanism, accompanied by the release of light metals such as calcium, magnesium and sodium. The $\mathrm{pH}$ value, initial concentrations and extraction temperature were studied.

To improve the sorption properties, it is proposed to carry out the modification of sorption materials $[15,16]$. The dried algae U. fasciata to be carbonized is impregnated with solution of chloride salts such as calcium chloride for $24 \mathrm{~h}$ [17]. Accordingly, sufficient quantities were soaked well with $10 \%$ chloride solution of $5 \mathrm{~L}$ capacity, respectively, so that the solution get well adsorbed for a period of $24 \mathrm{~h}$. At the end of $24 \mathrm{~h}$ the excess solution was decanted off and air dried. Then, the materials were placed in muffle furnace carbonized at $400{ }^{\circ} \mathrm{C}$. The dried materials were powdered and activated in a muffle furnace kept at $800^{\circ} \mathrm{C}$ for a period of $10 \mathrm{~min}$. After activation, the carbon was washed sufficiently with $4 \mathrm{~N} \mathrm{HCl}$ to remove the cations. Then, the materials were washed with plenty of water to remove excess acid, dried and powdered.

\section{Materials and methods}

The object of the study was the residual biomass of Lemna minor duckweed and Chlorella sorokiniana microalgae, which is formed after the extraction of valuable components, such as lipids, pigments, pectin substances [18].

We have previously studied the problems of the cultivation of the biomass of microalgae Chlorella sorokiniana and duckweed Lemna minor as a source of valuable components. Residual biomass, which is formed as waste, requires further utilization. It is proposed to use the residual biomass as a sorption material for the purification of waste water from heavy metal ions (zinc, cadmium, lead). The material is loose and inconvenient during operation, therefore, to increase the sorption capacity and shape, it is proposed to add chitosan.

TEG and millet husk are widely known as sorbents for the extraction of heavy metals. This article compares the sorption properties of sorbents of different composition.

Granules of 3 types were obtained by the technology described below:

Sample No1 - thermally expanded graphite (TEG) $(5$ g)- Residual microalgae biomass (RMB) (5 g) - chitosan $(100 \mathrm{ml})$;

Chitosan $40 \mathrm{~g}$ was dissolved in 3\% acetic acid 960 $\mathrm{ml}$. The mixture is stirred for $4-5 \mathrm{~h} 3 \%$ ours until complete dissolution of chitosan, add TEG and RMB. Then, the resulting gel-like mixture is poured dropwise through a syringe into a $5 \%$ sodium hydroxide solution $(\mathrm{NaOH})$. The formed granules are incubated for 24 hours in an alkali solution $(\mathrm{NaOH})$, followed by washing with water to a $\mathrm{pH}$ of 7.0-7.5. The drying of the granules was carried out at room temperature [19-20].

Sample No2 - RMB (5 g)- chitosan (100 ml). Chitosan $40 \mathrm{~g}$ was dissolved in 3\% acetic acid $960 \mathrm{ml}$. The mixture is stirred for $4-5 \mathrm{~h} \mathrm{3 \%}$ ours until complete dissolution of chitosan, add RMB ( $5 \mathrm{~g}$ ), further, the process of preparation is the same as that of the sample No1.

Sample No3- RMB (5 g) - chitosan (100 ml)- millet husk (5g). Chitosan $40 \mathrm{~g}$ was dissolved in $3 \%$ acetic acid $960 \mathrm{ml}$. The mixture is stirred for $4-5 \mathrm{~h} 3 \%$ ours until complete dissolution of chitosan, add RMB (5 g) and millet husk $(5 \mathrm{~g})$, further, the process of preparation is the same as that of the sample No 1.

The manufacture of samples No. 2.3 differs only in the composition of the added additives.

Sample No 0- Residual microalgae biomass without modification.

Chitosan- is an amino saccharide, a polysaccharide derivative. macromolecules consist of randomly-linked $\beta$ - (1-4) D-glucosamine units and N-acetyl-Dglucosamine (Figure 1).

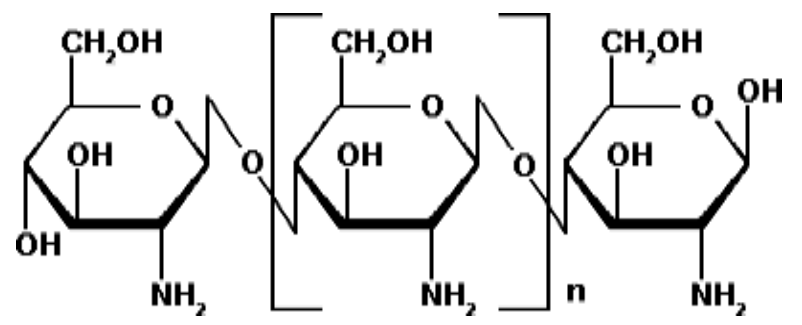

Fig. 1. Structural formula of chitosan.

Residual biomass and agricultural waste were previously thermally treated in a special steel cell with limited oxygen access. The residual biomass was burned at a temperature of $400^{\circ} \mathrm{C}$ for 20 minutes and the waste of agriculture at a temperature of $300^{\circ} \mathrm{C}$ for 20 minutes.

Structure of adsorbents by mean of scanning electron microscope Zeiss Leo 1530.

Specific surface of the granulated sorbents are study using NOVA 4000e. Surface area \& Pore Size Analyzer, brand Quantachrome.

$$
\frac{p / p_{0}}{a\left(1-p / p_{0}\right)}=\frac{1}{a_{m} C}+\frac{(C-1) p / p_{0}}{a_{m} C}
$$

where $p / p_{0^{-}}$is the ratio of the pressure in the system to the condensation pressure, $a$-is the amount of adsorption, $a_{m}$-is the volume of the monolayer on the surface of the adsorbent, $\mathrm{C}$-is the ratio of the adsorption equilibrium constants in the first layer and the condensation constant.

The residual concentration of heavy metal ions was determined by the voltammetric method (Russian standart 14.1:2:4.222-06) on the device TA-Lab. The accuracy of the measurement procedure is $5 \%$. To calculate the sorption capacity, model solutions were prepared with a concentration of $1 \mathrm{~g} / \mathrm{l}$. The sorption capacity was calculated as the difference between the initial and equilibrium concentrations, taking into account the mass of the sorbent and the volume of the 
solution. The accuracy of the measurement procedure is $5 \%$.

To modify the residual biomass after the extraction of valuable components, heat treatment is used, which allows to obtain a material with high sorption properties

\section{Results and Discussion}

To determine the sorption capacity, sorption was carried out for 20 minutes, at the rate of $2 \mathrm{~g}$ of sorption material per 1 liter of a model solution containing heavy metal ions (zinc, cadmium, lead). The mixture was stirred using a laboratory shaker. The calculation of the sorption capacity was carried out according to the formula (1) and the results are presented in table 1.

$$
q=\frac{C o-C e}{m} \cdot V
$$

Where $\mathrm{q}$ is the sorption capacity, Co and Ce are the initial and final concentrations of heavy metals in the solution, $\mathrm{V}(\mathrm{L})$ is the volume of solution and $\mathrm{m}(\mathrm{g})$ is the waste amount.

From table 1 it can be seen that the sorption material No. 3 has the highest sorption capacity; its specific surface is $2.720 \mathrm{~m}^{2} / \mathrm{g}$. The specific surface is not large, but the layered structure suggests that the extraction of metal ions occurs due to chemisorption and physical sorption. From microstructural studies, it follows that the samples have a layered structure characteristic of an additive made of chitosan. The sorption properties are also due to surface irregularities (cracks).

Table 1. Sorption properties of granular materials.

\begin{tabular}{|c|c|c|c|}
\hline \multirow{2}{*}{ Type } & \multicolumn{3}{|c|}{$\mathbf{q , ~} \mathbf{m g} / \mathbf{g}$} \\
\cline { 2 - 4 } & $\mathrm{Pb}^{2+}$ & $\mathrm{Cd}^{2+}$ & $\mathrm{Zn}^{2+}$ \\
\hline $\begin{array}{c}\text { Residual microalgae } \\
\text { biomass } \\
\text { Sample No 0 }\end{array}$ & 13.0 & 10.0 & 5.0 \\
\hline Sample No 1 & 22.0 & 17.0 & \\
\hline Sample No 2 & 28.5 & 16.0 & 26.3 \\
\hline Sample No 3 & 32.0 & 22.4 & 27.0 \\
\hline
\end{tabular}

Sample No. 1 illustrates the worm-like structure and packed layers of expanded graphite. As a result of thermal expansion, furrows or open channels can serve as pores and facilitate the adsorption of metals in them.

At the same time, the presence of chitosan in the analyzed adsorbents shows a porous and rough structure, which can provide a higher surface area and higher adsorption properties. As its chemical analogue (cellulose), chitosan has a similar fiber morphology with distinct crystallites and holes in the shape of domes.

Figures $2 \mathrm{C}$ show micrographs of an adsorbent from millet husks of irregular shape. The surface structure appears to be heterogeneous, which can be explained by the presence of lignin in this adsorbent. On its outer surface there are cavities that can be called irregular and inhomogeneous. Some of the pore holes and cracks may contribute to the flow of model solutions into the pores.

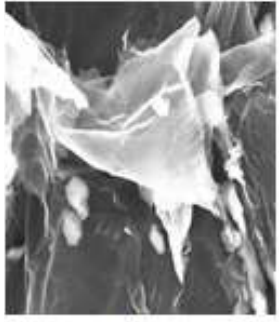

a

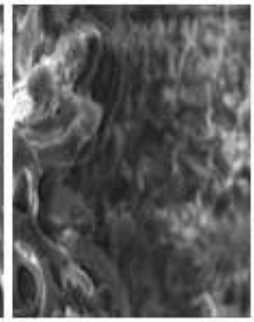

b

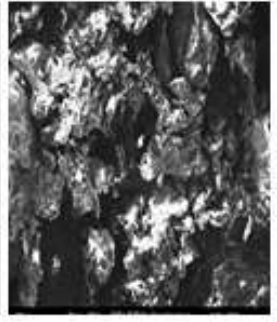

C
Fig. 2. Surface morphology sample No1 (a) and sample No2 (b), sample No3 (c).

For a comparative analysis of the porosity of the samples, the specific surface area was determined by the BET method. (table2).

Table 2. The specific surface of the granulated sorbents.

\begin{tabular}{|c|c|}
\hline Granular sorbent & $\mathbf{S ~ s p}, \mathbf{~ m}^{2} / \mathbf{g}$ \\
\hline $\begin{array}{c}\text { thermally expanded graphite - } \\
\text { Residual microalgae biomass - } \\
\text { chitosan }\end{array}$ & 1.093 \\
\hline $\begin{array}{c}\text { Residual microalgae biomass - } \\
\text { chitosan }\end{array}$ & 1.599 \\
\hline $\begin{array}{c}\text { Residual microalgae biomass - } \\
\text { chitosan- millet husk }\end{array}$ & 2.720 \\
\hline
\end{tabular}

From table 2 it can be seen that the specific surface values are not large, and the highest value for sample No 3. It is possible that sorption processes occur due to chemical sorption. The specific surface area is consistent with the value of sorption capacity for all samples.

\section{Conclusions}

1. It is proposed to use as a sorption material the residual biomass obtained after the extraction of valuable components from microalgae Chlorella sorokiniana and Lemna minor duckweed.

2. Granulated materials were obtained with the addition of thermally expanded graphite, chitosan and agricultural waste.

3. The sorption properties of the materials obtained were studied, the values of the sorption capacity for lead, cadmium and zinc ions were calculated.

\section{References}

1. YAO Zhigang, et al., High efficiency of heavy metal removal in mine water by limestone, Chin. J. Geochem 28, 293-298 (2009).

2. A. Chatterjee, S. Schiewer, Effect of Competing Cations $(\mathrm{Pb}, \mathrm{Cd}, \mathrm{Zn}$, and $\mathrm{Ca})$ in Fixed-Bed Column Biosorption and Desorption from Citrus Peels, Water Air Soil Pollution 1854, 225-238 (2014).

3. C. Suhong, et al., Adsorption of hexavalent chromium from aqueous solution by modified corn stalk: A fixedbed column study, Bioresource Technology 113, 114-120 (2012).

4. H. Gogoi, et al., Removal of metals from industrial wastewater and urban runoff by mineral and bio- 
based sorbents, J. Environmental Management 209, 316-327 (2018). DOI: https://doi.org/10.1016.

5. A. Sukru, et al., Adsorption of Heavy Metals Onto Waste Tea, European Scientific Journal, April, 111117 (2016).

6. N. Meenaksh, et al., Tea Wastes as a Sorbent for Removal of Heavy Metals from wastewater, International J. Current Engineering and Technology 4, 243-247 (2014).

7. A. Ratna Kumari, K. Sobha, Removal of lead by adsorption with the renewable biopolymer composite of feather (Dromaius novaehollandiae) and chitosan (Agaricus bisporus), Environ. Technol. Innov. 6, 1720-1724 (2016).

8. A. Ratna Kumari, et al., Cost effective and ecofriendly method for copper removal by adsorption with Emu feather (Dromaius novaehollandiae) and chitosan (Agaricus bisporus) composite, Int. J. Chem. Tech. Res., 8, 4, 1769-1782 (2015).

9. A. Naga Babu, et al., Removal of lead and fluoride from contaminated water using exhausted coffee grounds based bio-sorbent, J. Environmental Management 218, 602-612 (2018).

10. Y. Vijaya, et al., Modified chitosan and calcium alginate biopolymer sorbents, Carbohydrate Polymers 72, 261-271 (2008).

11. L.C. Ajjabi, L. Chouba, Biosorption of $\mathrm{Cu} 2+$ and $\mathrm{Zn} 2+$ from aqueous solutions by dried marine green macroalga Chaetomorpha linum, Journal of Environmental Management 90, 3485-3489 (2009).

12. E. Romera, et al., Comparative study of biosorption of heavy metals using different types of algae, Bioresource Technology 98, 3344-3353 (2007).

13. Li Mengling, et al., Algae-based sorbents for removal of gallium from semiconductor manufacturing wastewater, Clean Technologies and Environmental Policy 20, 899-907 (2018).

14. A.H. Sulaymon, et al., Competitive biosorption of lead, cadmium, copper, and arsenic ions using algae, Environ Sci Pollut Res 20, 5, 3011-3023 (2013). DOI: https://doi.org/10.1007/s11356-0121208-2.

15. A. Imran, et al., Low cost adsorbents for the removal of organic pollutants from wastewater, Journal of Environmental Management 113, 170-83 (2012).

16. M.Nadeem, M. Shabbir, M.A. Abdullah, Sorption of cadmium from aqueous solution by surfactantmodified carbon adsorbents, Chem. Eng. J. 148, 365-370 (2009).

17. R.P. Suresh Jeyakumar, V. Chandrasekaran, Adsorption of lead (II) ions by activated carbons prepared from marine green algae: Equilibrium and kinetics studies, Int. J. of Industrial Chemistry (Springer) 5, 10 (2014).

18. N. Politaeva, et al., Impact of various physical exposures on Chlorella Sorokiniana microalgae cultivation, International J. Applied Engineering Research 12, 21, 11488-11492 (2017).

19. N.A. Politaeva, et al., Granulated sorption materials for waste waters purufucation from zink ions $(\mathrm{Zn} 2+)$, News of higher educational institutions. Series: Chemistry and Chemical Technology 60, 7, 85-90 (2017).

20. E.A. Taranovskaya, N.A. Sobgaida, D.V. Markina, Technology for obtaining and using granulated absorbents based on chitosan, Chemical and Petroleum Engineering 52, 5-6, 357-361 (2016). 